\title{
NO FUNDO DA MATA VIRGEM: a complexidade de um elemento mítico no imaginário ocidental sobre a natureza
}

\author{
Ely Bergo de Carvalho*
}

\section{Resumo}

A mata virgem é um elemento recorrente no imaginário social brasileiro. Embora já se tenha provado o equívoco de se considerar areas florestais "virgens", a ação humana, mesmo que indireta, deixou marcas por todo o planeta. Este ensaio procura, justamente, compreender os motivos da persistência da expressão mata virgem em nosso imaginário. Postula-se que mata virgem é parte de um mito moderno sobre a natureza; é um "malentendido" pertencente a uma cultura etnocêntrica; é uma ideologia justificadora da dominação ocidental; é uma representação apropriada e reelaborada em diferentes configurações sociais; é um elemento de longa duração, ancorado na disjunção da natureza e da cultura, que faz parte da visão de mundo hegemônica no Ocidente.

Palavras-chave: Mito. Representação. Natureza.

Para chegar ao fundo de “"mata virgem” é necessário escavar grossas camadas de memória que compõem o nosso imaginário sobre a natureza (SCHAMA, 1996: 27). A expressão mata virgem ainda é amplamente utilizada no senso comum, às vezes como sinônimo de floresta primária ou para indicar uma floresta que, simplesmente, esteja em pé, independentemente de seu estado de antropização. É uma expressão dicionarizada, assim expressa: "Mata virgem. 1. Bras. Floresta natural e primitiva, ainda não explorada: 'Era um alto jequitibá, relíquia da antiga mata virgem’ (José de Alencar, O Tronco do Ipê, p. 172). (NOVO Aurélio, 200?.)”.

A imagem de mata virgem remete a uma pureza, a uma não-corrupção, presente na valoração da virgindade feminina no mundo ocidental, que pode ser interpretada a partir de uma chave psicologizante, mas o que aqui se pretende destacar refere-se à conotação de nãoexploração “produtiva” e à não-presença humana na paisagem.

\footnotetext{
* Doutor em História pela Universidade Federal de Santa Catarina. Professor da Universidade Federal de Mato Grosso. E-mail: carvalho2010@yahoo.com.br
} 
Nos meios acadêmicos especializados, há muito já se fez crítica sobre a ideia de mata virgem. Biogeógrafos, ecólogos, historiadores ambientais, dentre outros já demonstraram a falácia de se imaginar uma natureza prístina, intocada pelos seres humanos. Já foi demonstrado existirem milhares de quilômetros de florestas antropogênicas; que a presença das populações indígenas alterou profundamente a floresta durante milhares de anos (MORAN, 1994; ALTIERI, 2002). Quando, na atualidade, lembramos da presença de biocidas nos mais longínquos ecossistemas antárticos e dos efeitos globais das transformações que o ser humano está gerando no planeta, temos que admitir:

[...] objetivamente, a atuação dos vários ecossistemas que sustentam a vida no planeta independe da interferência humana, pois eles já estavam agindo antes da caótica ascendência do Homo sapiens. Mas também é verdade que nos custa imaginar um único sistema natural que a cultura humana não tenha modificado substancialmente, para melhor ou para pior. E isso não é a obra apenas dos séculos industriais. Vem acontecendo desde a antiga Mesopotâmia. É contemporâneo da escrita, de toda a nossa existência social. E esse mundo irreversivelmente modificado, das calotas polares às florestas equatoriais, é toda a natureza que temos (SCHAMA, 1996: 17).

Desta forma, embora haja pesquisas sistemáticas desde, pelo menos, a década de 1970, demonstrando o equívoco da imagem mata virgem, ainda é comum encontrarmos em eventos científicos e em artigos especializados a volta atávica a mata virgem. Partindo de uma trajetória particular de pesquisador da história ambiental do Brasil, o objetivo deste ensaio é, justamente, compreender os motivos da persistência e o contínuo retorno da imagem mata virgem. Consideramos insuficientes as explicações sugeridas diante da constatação de tal persistência, como: o desconhecimento de cientistas que deveriam "conhecer mais profundamente a [bibliografia sobre e a] realidade” (TOMAZI, 1999: 54) que analisam ou por uma dimensão ideológica da mata virgem.

Sem dúvida, é possível pensar mata virgem como um elemento que faz parte do "mito moderno da natureza intocada”. Ou seja, a produção dessas representações sobre o espaço fazem parte de um mito (sistema explicativo pautado no pensamento simbólico) de uma “natureza intocada”.

Para Diegues (1998), tal mito teria por base: 1 - o motivo edênico presente no imaginário ocidental; 2 - a tradição romântica ou a oposição ao Iluminismo, que pensavam a Razão como a ordem que deveria se impor ao caos da natureza; 3 - um terceiro elemento, apontado por ele, com base em Keith Thomas, não sobre a formação, mas para entender a permanência do mito: “A persistência da idéia [sic] de um mundo natural, selvagem, não 
tocado, tem força considerável, sobretudo entre populações urbanas e industriais que perderam, em grande parte, o contato quotidiano e de trabalho como o meio rural" (DIEGUES, 1998: 157).

O pensamento mítico faz parte do "Ser" de um dado tipo de sociedade arcaica. Todavia, pelo menos desde Levi-Strauss, abandonou-se a ideia que ele é uma forma inferior de pensamento, de sociedades chamadas pejorativamente de "primitivas", em oposição ao pensamento racional de nossa sociedade moderna (MORIN, 1996: 144). Schama (1996, 24), por exemplo, demonstrou o quanto nossa sociedade moderna ocidental mantém seus mitos em sua relação com a natureza. Todavia, na sociedade dita moderna há diferenças a serem consideradas no seu pensamento mítico. A primeira, talvez, seja que na trajetória da sociedade ocidental houve uma oposição entre mito e razão, mesmo que o mais importante seja perceber que:

[...] embora os nossos espíritos sejam muito diferentes do dos arcaicos ou dos medievais, embora os dois pensamentos se tenham tornado antagonistas, vivemos, não só a sua oposição, mas também a sua coabitação, as suas interações e as suas trocas clandestinas e quotidianas (MORIN, 1996: 145).

É na linguagem que mitos e logos se encontram e se produzem, antes de sua separação, mas sociedades diferentes produzem de formas diferentes estas interações e separações. Morin $(1996,157)$ expõe:

Temos que compreender que o pensamento mitológico evoluiu, deslocou-se, transformou-se e produziu neomitos, que se fixam em idéias [sic]. O neomito reintroduz a explicação pelo vivo, o singular, o concreto onde reina a explicação pelo físico, o geral, o abstracto. Mas é o concreto vivido que, infiltrando-se na idéia [sic] abstracta ou geral, o torna viva. Não reintroduz os deuses e os espíritos. Espiritualiza e diviniza a idéia [sic] a partir do interior. Não retira necessariamente o sentido racional da idéia [sic] parasitada. Inocula-lhe uma sobrecarga de sentido, que a transfigura.

Desta forma, no mundo moderno não é a natureza que ganha "vida”, e sim as ideias. Os mitos procedem do transbordamento de sentidos. A ecologia pode classificar racionalmente a floresta por seus estados de sucessão ecológica natural, considerando a “comunidade/floresta clímax”, quando a comunidade atinge seu grau máximo de desenvolvimento e equilíbrio, mas a busca da "pureza" da "virgindade incorrupta pela mão humana” está sempre a contaminar as classificações objetivantes.

Destarte, não se trata aqui de efetuar uma caça de aniquilação dos mitos. A questão é demonstrar a sua operacionalidade específica em uma sociedade moderna. Como afirma Kalampalikis (2009, 112): 
Pensar os mitos nas sociedades modernas, moldadas pelo saber científico, a empiria e a verificação, seria vão, senão quimérico. Por outro lado, adotar ao pé da letra a crítica positivista que quer reduzir mito a um gênero literário ou a uma fabulação arcaica seria ignorar sua relação com a experiência social, cultural e imaginária. Ao contrário, esclarecer as formas simbólicas do saber que as representações veiculam em si sob a forma de um imaginário coletivo, herdado, expresso, mediado, compartilhado e, sobretudo, vivenciado em sociedade seria atualmente mais apropriado, senão necessário.

Não se trata de excluir a categoria mito, pois, tal como afirma Moscovici (2009, 21), os mitos devem ser entendidos como articuladores das representações sociais; mais que destruir o mito, temos que entender sua historicidade. Ginzburg (1991) chama a atenção para atentarmos para a historicidade dos mitos e, com isso, entendermos o papel inventivo dos atores sociais em sua reprodução e reelaboração. Ao estudar “mitos e ritos”, o citado autor afirma:

[...] sua transmissão é, como a das estruturas profundas da linguagem, inconsciente - mas sem que isso implique a presença de um inconsciente coletivo. O mito ou o rito transmitidos por meio de mecanismos históricos contêm implicitamente as regras formais de sua própria reelaboração (GINZBURB, 1991, 248).

Não é pretensão aqui chegar às "regras formais” da elaboração de um mito, mas apenas apontar para os elementos de sua transmissão e para os elementos profundos da manutenção de um de seus elementos, pois, se o mito faz parte da produção científica moderna, como afirma Morin (1999), a mera designação de algo como mítico não explica seu processo de permanência no tempo. É necessário compreender a complexidade do fenômeno abordado.

Aqui, tal como Morin (1999, 29-31), compreendemos complexidade não apenas em oposição ao paradigma cartesiano/moderno que apostava na simplicidade, em que haveria um elemento simples e objetivável, ao qual a realidade poderia ser reduzida e a partir do qual fosse possível a intervenção e controle humano da realidade; não apenas apostamos que o mundo não é essa “máquina simples”, mas compreendemos que a complexidade deriva, antes de tudo, da própria produção social da realidade. Entender os motivos da continuidade da mata virgem, antes de um estudo sobre os ecossistemas florestais e suas interações com os seres humanos, é uma interpretação da forma como foi/é construída a imagem de mata virgem. Para tal, dividimos o presente ensaio em cinco proposições, quais sejam: um "malentendido" cultural; ideologia da virgindade; uma representação cristalizada; um elemento de longa duração; e disjunção natureza x cultura. 


\section{I - Um “mal-entendido” cultural}

Mata virgem é um “mal-entendido cultural”, ou seja, é fruto da relação entre diferentes concepções do que seja terra utilizada e ocupada.

Por exemplo, a agricultura de coivara, que é a prática de queimar a floresta, cultivar a terra e, quando a área da "roça” é infestada por organismos concorrentes (“pragas”) e a produtividade se reduz pela degradação do solo, a área é entregue à floresta para sua recomposição e se avança sobre uma nova área florestal. Tal forma de cultivo, amplamente utilizada em todas as regiões tropicais do planeta, quando exercida em certas condições - em especial baixa densidade populacional - é considerada, hoje, não-prejudicial ao ecossistema, ou pelo menos permite a manutenção da floresta em pé. Todavia, como o campo de cultivo não é "limpo", a imagem da paisagem aparenta, dentro de nossa tradição ocidental, que ele não é “aproveitado". Ainda mais distante do modelo moderno/ocidental são as formas de apropriação de sociedades caçadoras e coletoras, que podem combinar a coleta com a disseminação de certas plantas, criando um habitat mais propício à sua sobrevivência. Todas estas formas de apropriação da natureza podem ser tomadas por olhos eurocêntricos, que reconhecem como “utilizado” apenas o “campo limpo”, como não-utilização um “desperdício de terras”.

O modo etnocêntrico do que seja pensar a "utilização" de uma área, às vezes, foi produzido como reforço de fenômenos específicos que contribuíam para os ocidentais não reconhecerem, na paisagem, as marcas da presença humana. Por exemplo, na conquista colonial da América, algumas vezes, as epidemias iam à frente dos conquistadores; desta forma, quando chegaram a uma dada região, a população local havia morrido ou fugido (COSTA, 1990).

É importante lembrar que, ainda hoje, são muito comuns, no senso comum, afirmações do tipo: “por que índio precisa de tanta terra?” Como o padrão de utilização da terra é a lavoura homogeneizada, outras formas de apropriação (o extrativismo, a coivara, a caça e a coleta) não são reconhecidas e, portanto, deslegitimadas como desuso ou despovoamento.

\section{II - Ideologia da virgindade}

Desta forma, tal “mal-entendido cultural” está intrinsecamente ligado à produção da imagem de um “vazio demográfico”, na qual uma região é apresentada como sem população, 
com uma baixa população ou, ainda, como uma área em que a população não utiliza os recursos lá existentes. Qualquer um destes argumentos serviu por séculos e, ainda serve, para justificar a conquista e subjugação do território do “Outro”. Tal ideologia ajudou a criar e a justificar a expansão da sociedade ocidental sobre outros grupos e sociedades.

Como afirma Thomas (1996, 19), por exemplo, os ingleses, no século 17, afirmavam, em relação à Irlanda, que seus habitantes fracassaram na exploração das terras irlandesas, pois consideravam moralmente incorreto manter a terra inculta, o que justificaria o domínio inglês na ilha vizinha. Não podemos separar o que os seres humanos do passado pensam a respeito do mundo natural daquilo que pensam sobre si mesmos e sobre o "Outro".

A agricultura [para os ocidentais] estava para a terra como o cozimento para a carne crua. Convertia natureza em cultura. Terra não cultivada significava homens incultos. E quando os ingleses seiscentistas mudaram-se para Massachusetts, parte de sua argumentação em defesa da ocupação dos territórios indígenas foi que aqueles que por si mesmos não submetiam e cultivavam a terra não tinham direitos de impedir que outros o fizessem (THOMAS, 1996, 17).

Assim também ocorria no Brasil no século 18, ao buscar compreender a forma etnocêntrica de como as narrativas das expedições eram construídas. Corrêa (2008) observa que, conhecendo o território indígena, as expedições se afastam de tais territórios e, ao mesmo tempo, descrevem a paisagem como deserta da presença humana. Um logro criado também pela ação indígena que, às vezes, abandonava as aldeias percebendo a chegada dos soldados. Assim, os conquistadores apresentavam, partindo de uma noção circunscrita de território indígena - sem considerar os deslocamentos inerentes ao seu modo de vida - como se os indígenas estivessem adentrando o território dos colonos e não o contrário, como de fato ocorria. Concluindo, a autora afirma:

A ausência de homens e mulheres e de cultura nesses cenários, [...] é uma ilusão produzida pelo narrador devido a sua decodificação da paisagem e tendo em vista seus interesses imediatos. A existência de desertos validou e justificou a sua apropriação (CORRÊA, 2008:150).

No século 20, no Paraná, uma empresa colonizadora, mesmo tendo claros relatos e indícios da presença indígena em terras de sua propriedade, omitiu tal informação, assim como a informação da presença de posseiros/“caboclos” nas terras. Afirmava, ainda, ter terras livres de qualquer conflito e que poderia vender a terra sem o perigo de serem griladas ou expropriados pelos que antes controlavam aquele território. Propagandeou fortemente a 
afirmação de ter terras com “certeza de lucro e direito de propriedade”, mesmo que tivesse que manter um grande aparato de vigilância e violência, e omitir certas provas da presença indígena para manter tal imagem (TOMAZI, 1999).

Por mais que a crise ambiental e a luta dos movimentos sociais tenham colocado populações tradicionais (indígenas, seringueiros, etc.), com suas formas diferenciadas de apropriação dos recursos naturais na ordem do dia, no debate político atual, ainda não é incomum encontrar áreas em disputa entre aqueles que tentam reproduzir a indústria da grilagem, afirmando que tal área é, ou era, uma mata virgem e, portanto, possuem o direito de propriedade sobre elas, e não aqueles que antes estavam sobre a terra e mantinham a mata em pé, mas sem o título de propriedade.

Todavia, não podemos entender a persistência desse elemento, mata virgem, como mero reflexo de interesses, ou seja, devemos levar os elementos culturais a sério, como geradores de ação e não como uma espécie de "glace do bolo" que enfeita as "reais motivações”. Como afirma Elias (1997, 278):

Havia então, e ainda há hoje, uma tendência generalizada a subestimar as convicções políticas e sociais, para vê-las como mero palavrório - como 'ideologias' que têm como única substância em sua base, os 'interesses' dos grupos portadores, como estes são definidos em seu próprio entendimento. De acordo com esse pressuposto, as ações e finalidades de unidades sociais devem ser explicadas, em primeiro lugar, por referência aos atuais 'grupos de interesses', ao passo que as metas e as doutrinas expressas só têm um valor explicativo secundário, na medida em que servem a esses interesses, que eles freqüentemente [sic] escondem.

Um mito é um fenômeno complexo (MORIN, 1996: 153). Apesar de mata virgem ter uma função ideológica, enquanto utilização de formas simbólicas para manter e justificar relações sociais assimétricas de forma mais ou menos consciente, ela não se deixa apreender apenas nessa perspectiva.

\section{III - Uma representação cristalizada}

Mata virgem é uma representação cristalizada que, como tal, tende a se reproduzir em nossos modelos narrativos, mesmo que seja apropriada e consumida de forma diferente, segundo um conjunto de relações de forças em cada configuração em que ela emerge.

No caso em tela, em geral, está associada a “vazio demográfico”. Um bom exemplo é o famoso mapa, que ainda aparece em muitos livros didáticos, da América do Sul, com o 
tratado de Tordesilhas e as Capitanias Hereditárias portuguesas. A parte ocidental é apresentada em branco, pois lá não haveria “nada”, apenas mata virgem. Nesse tipo de mapa, apenas os elementos que indicam a presença e o domínio europeu na América são indicados; todo o resto é silenciado.

Outros bons exemplos são as lembranças de agricultores, em geral familiares e que adotaram o padrão tecnológico da chamada "Revolução Verde”, do interior do Paraná, sobre a floresta que dominava o noroeste do estado até a década de 1950 - hoje uma das áreas mais desflorestadas do Brasil. Para eles, a floresta era um sertão, e mata virgem sinônimo de sertão: onde “era sertão, era tudo mato”. E mais:

A floresta é 'mato' e 'mato' é um 'nada'. A floresta era o antônimo de 'tudo' o que era conhecido para eles, era a não-estrada, a não-casa, a não-lavoura.

A floresta era um obstáculo a ser superado, um 'nada', um marco zero a partir do qual se constrói a história da realização do sonho geral de se tornar ou manter-se proprietário rural - ou simplesmente de 'ficar rico' (CARVALHO; NODARI, 2007, 283).

Era um lugar deserto e "virgem", apesar da presença de indígenas e posseiros que ocupavam e exploravam a região, quando da chegada da empresa que colonizou o município estudado, nas décadas de 1940 a 1960.

Todavia, para alguns agricultores, a floresta é lembrada como espaço de liberdade em relação a patrões, no qual poderiam exercer plenamente sua autonomia e autoridade de serem “pais”, por meio do acesso à terra e do sustento da família, com a exploração de recursos abundantes, como a caça, por exemplo (CARVALHO; NODARI, 2007: 283; CARVALHO, 2008).

Outro estudo, de Ribeiro (2006), abordou sertanejos da zona de Cerrado, em Minas Gerais, que identificou o sertão como algo que estaria deserto. Mesmo aqueles que moram em regiões identificadas como sertão, sempre identificam o sertão como mais à frente, em alguma área despovoada mais adiante:

Ninguém respondeu que o sertão era ali, onde ele morava [...]. Dos naturalistas do século XIX a Guimarães Rosa, o sertão é sempre mais além, mais para o interior [...]. Se eu vivo aqui, este lugar não pode ser um deserto, ele deve estar mais adiante, onde a sociedade humana ainda não venceu 0 mundo natural (RIBEIRO, 2006, 282).

Pioneiros da geografia moderna no Brasil também são bons exemplos da multiplicidade das formas de apropriação da representação da mata virgem. Aliás, a imagem 
de um “vazio demográfico”, que justifica a colonização, foi construída, em grande parte, tanto pela geografia como pela história moderna (MOTA, 1994, 17-44). Monbeing (1984) reafirma a representação que a região, por ele estudada no interior de São Paulo e do Paraná, era “vazia de população” antes da chegada da colonização moderna, ao afirmar que apenas os topônimos indicavam a presença indígena. "Nada subsiste dos antigos habitantes, a não ser de modo muito indireto” (MONBEING, 1984, 132). Mas é um autor que não cai no mito do bom selvagem ecológico e percebe a população indígena em sua capacidade de alterar profundamente o mundo natural:

[...] por mais espetacular que tenha sido o recuo da floresta, é preciso admitir que ela não tenha começado com a penetração pioneira moderna. Os fazendeiros teriam encontrado uma paisagem natural autêntica? Ora, é fora de dúvida que os indígenas já haviam atacado a vegetação primitiva. Praticavam culturas itinerantes usando queimadas, retirando a alimentação mais da agricultura do que da caça e da pesca e provavelmente atacando seriamente a floresta. Indicações dadas por etnógrafos permitem avaliar a importância das lavouras indígenas (MONBEING, 1984, 87-8).

Um geógrafo contemporâneo dele, Maack (1981), que tem uma obra seminal para a geografia física do Paraná, tem seu trabalho cheio de referências às “matas virgens”, em geral em oposição a “mata secundária”, já antropizadas (MAACK, 1981, 203).

Para entender a forma como Maack (1981) considerava mata virgem, é importante destacar que se buscou aprovar, na década de 1950, pela Assembleia Legislativa do Estado do Paraná, a constituição de um Parque Florestal Estadual da Serra dos Dourados, que abrangeria uma faixa de 70 quilômetros, na margem esquerda do rio Paraná, na altura do rio Ivaí. Maack (1981) foi o responsável por embasar a proposta de criação do Parque Florestal Estadual na Serra dos Dourados, e o fez com base na defesa da preservação da fauna e da flora. Propunha também que a população indígena Xetá fosse preservada como "um complemento da paisagem natural” (SILVA, 1998, 205). Apesar de o parque não ter sido criado efetivamente, tal fato é revelador do mito, do bom selvagem ecológico, que é uma desumanização do “Outro”, pois o percebe como parte da natureza.

Autores da segunda metade do século 20, como Bernandes (1953, 23), combinavam a afirmação da presença da mata virgem a outros elementos que reforçam a representação de um “vazio demográfico” com a identificação, às vezes explícita, da presença da população indígena ou de posseiros não-indígenas. Não vêem nisso contradição, talvez porque a "baixa população” e, fundamentalmente, a suposta não-utilização da terra (pois terra utilizada só é 
entendida como "terra limpa”) justificavam tal perspectiva etnocêntrica e produtivista da paisagem.

\section{IV - Um elemento de longa duração}

Se mata virgem é uma representação, constantemente apropriada e reelaborada em diferentes configurações sociais, como se argumentou, sua força não pode ser compreendida sem considerar ser ela um elemento de longa duração. Ou seja, conforme tal representação foi apropriada e reelaborada por diferentes configurações sociais, gerou-se um efeito de reforço da representação, mesmo que em discursos, às vezes, bastante diferentes (SAHLINS, 2006).

A narrativa seminal de mata virgem talvez esteja na tradição judaico-cristã, consolidada na narrativa bíblica, pois, no imaginário judaico-cristão, sem dúvida mata virgem está associada à ideia da existência de um paraíso terrenal do qual o ser humano foi expulso.

Todavia, tal motivo edênico não deva ser tomado como um todo homogêneo, mas ser entendido na longa duração no imaginário social (HOLANDA, 1996). Em geral, os elementos de longa duração não se mantêm por serem sempre iguais a si mesmos, mas por terem sido apropriados em diferentes configurações sociais, em diferentes contextos, nos quais eles são reelaborados e, neste processo, muitas vezes, se amplificam. Mas não entendemos a força de tais elementos se não percebermos que eles se legitimam e tiram força de uma tradição de longa duração (SAHLINS, 2006). Dessa forma, Pero Vaz de Caminha, ao afirmar que "nesta terra em se plantando tudo dá”, procurava agradar ao rei, oferecendo-lhe boas notícias, lembrando sua majestade, com isso, daquele súdito que lhe escrevia e que seria merecedor de suas mercês, além, é claro, de projetar na América a visão edênica medieval de que era portador. A propaganda de venda de terras por empresas colonizadoras, na fronteira agrícola brasileira nos séculos 19 e 20, ao afirmar estarem vendendo terras ubérrimas cobertas por mata virgem, estavam querendo, antes de tudo, vender terras. Todavia, essas e outras apresentações formam uma tradição edênica, apesar de serem textos em contextos bem diferentes.

Casos como esse podem ter levado Burke (2000) a afirmar que, em sua opinião, por mais que haja um processo permanente de ressignificação:

[...] é praticamente impossível escrever história cultural sem tradição, contudo está mais do que na hora de se abandonar o que se pode chamar de noção tradicional de tradição, modificando-a para levar em consideração a 
adaptação, assim como o reconhecimento, e recorrendo às idéias [sic] da teoria da 'recepção’ (BURKE, 2000, 240-1).

Portanto, é legítimo reconhecer a expressão mata virgem como parte da grande narrativa civilizatória do Ocidente, que silencia o "Outro" e o reconhece apenas como inexistente ou incapaz de produzir história, gerando um efeito que procura vedar ao "Outro" o poder de efetuar a sua própria narrativa, de tal forma que, mesmo os que criticavam o imperialismo ocidental, mantinham as regiões “exóticas” “vazias”, em uma "visão de mundo imperialista, pois nada havia de não-europeu acessível aos olhos” (SAID, 1995, 56, 13).

Um exemplo de conceber mata virgem a partir dessa concepção pode ser encontrado ao abordar o imaginário sobre a natureza durante o processo de colonização moderna no estado do Paraná:

Outro elemento recorrente na concepção de natureza nas fontes abordadas é a sua virgindade. Vários autores já apontaram o equívoco da idéia [sic] de 'mata virgem'. Todavia, ainda hoje, qualquer remanescente de floresta que pareça primária ainda pode ser denominado de 'mata virgem', mesmo que tenha apenas uns poucos hectares e já esteja bastante degradada. Tal tipo de afirmativa era ainda mais usada no período da colonização dirigida. O relatório de Departamento de Geografia Terras e Colonização, datado de 1954, afirma que a Gleba 3 da Colônia Mourão era 'coberta de mata virgem'. Afirmava ainda que a referida gleba foi ocupada por nacionais de sobrenome ucraniano, muitos vindos da região de Mallet. Já no relatório do exercício de 1940 se afirmava que o serviço de colonização possuía o afã 'patriótico de incrementar o povoamento dos ínvios e virgens sertões do Brasil, objetivando o progresso econômico do país, fonte de renda para o erário público e riqueza para coletividade'. Longe de ser desprovido de caminho, havia muitos que conheciam as entradas e saídas do sertão e o exploravam para sua sobrevivência e/ou para o mercado internacional. Há aqui uma forma de silenciamento. O que alguns chamariam de um 'dispositivo de negação do Outro', não se trata apenas que o padrão para considerar algo ‘ocupado' é o desflorestamento, mas porque 'vê o Outro como não existente’ (CARVALHO, 2008: 153).

A distinção entre área "não-virgem" e uma mata virgem pode ser colocada como uma diferenciação na qual um poder diferenciador estabelece a dicotomia, sendo o segundo membro, o "Outro" do primeiro, não havendo, portanto, simetria entre os membros, uma vez que o poder diferenciador seria parte do primeiro termo (BAUMAN, 1999, 22). Os pares dicotômicos “moderno” versus “arcaico/atrasado”; “cidade/litoral/civilização/modernidade” versus sertão, podem ser interpretados dentro desta mesma dinâmica. Dessa forma deve ser entendida a representação da "área ocupada/produtiva/desflorestada" em relação a mata virgem. 
Mas tal solução não dá a devida historicidade ao fenômeno abordado. Por exemplo, a distinção mata virgem versus “terra ocupada” é mais forte no mundo urbano. Foi a devastação sistemática das florestas para transformá-las em campos de cultivo e pastagem, afastando os perigos reais da floresta, que permitiu melhor idealizar a "floresta” como um lugar idílico, onde o "homem" pode se recuperar das conturbações das cidades modernas em uma "volta a uma natureza primitiva e revigorante” (THOMAS, 1996; DIEGUES, 1998, 157).

Reconhecer a descontinuidade é tão importante como reconhecer as continuidades. Talvez seja esse um problema a pensar em termos de "dispositivos" e não em termos de processo, ou seja, dá-se ênfase às descontinuidades e se perdem as continuidades; às vezes, também a agência dos atores. Corrêa (2008), talvez, resvale no problema da homogeneização, mas ao mesmo tempo mostra um caminho para o problema em tela, ao afirmar que:

O brasileiro concebe as terras apossadas e utilizadas pelos índios entre os séculos XVI e XX da mesma forma que ela foi descrita por Pero Vaz de Caminha em 1500. Apesar de se afirmar serem elas habitadas, a paisagem retratada leva o leitor a imaginar uma natureza virgem. Se há muito já se criticou o caráter político-ideológico da visão sobre os índios como bárbaros e sobre as terras, especialmente além da fronteira da colonização européia [sic], como desertas, a insistência em descrever o espaço físico em separado de sua organização social naturaliza esse espaço e restaura a concepção sobre a imaturidade das culturas indígenas. Essa naturalização [...] significa a negação da História e implica uma desapropriação das pessoas que vivem nessas terras (CORRÊA, 2008, 136).

Ainda segundo Corrêa (2008, 136), o fato da quase inexistência de obras "historiográficas que descrevessem a paisagem da fronteira como humanizada explica que, apesar da crítica à idéia [sic] de um vazio social e cultural, essa representação continue a se reproduzir no imaginário do brasileiro”.

Humanizar a paisagem fronteiriça significa preencher o mapa citado, da linha do Tratado de Tordesilhas, com nomes das etnias indígenas que ocupavam o território atual do Brasil. Mas, mais importante, é compreender que a descrição de uma paisagem natural, em oposição a uma paisagem social, prejudica o nosso entendimento de paisagem (SILVA, 1997, 204). Impede-nos de entender que as florestas, que, às vezes, parecem “virgens” são, na verdade, fruto da ação humana durante milhares de anos, efetuando queimadas que favoreceram uma dada configuração vegetal, como no caso das florestas de bambu da Amazônia (SILVA, 1997, 210) e que, por outro lado, na paisagem mais urbanizada há uma dependência, material e simbólica, em relação ao mundo natural. A processualidade, ou seja, 
a historicidade dos processos de interação é fulcral para se entender cultura e natureza como elementos imbrincados e não dicotômicos (BERKES, 2005).

\section{V - Natureza e cultura: disjunção}

Mata virgem é o tipo de imagem fortemente ancorada na disjunção entre natureza e cultura. Tal disjunção é constitutiva de nossa visão de mundo moderna. Superar tal visão de mundo que nos constitui não é um ato de vontade individual, mas parte de um grande esforço social para transformar a forma como pensamos e lidamos com o ambiente em que vivemos.

Não cabe aqui fazer a genealogia desta disjunção e discutir se deveríamos situá-la a partir de Descartes (GRÜN, 1996), de Kant (MOTA, 1994, 10), do Iluminismo/Romantismo (DIEGUES, 1998, 157).

Tampouco cabe acreditar na visão de mundo mecanicista enquanto única, a qual teria tornado o ser humano desprovido de mitos e capaz apenas de uma racionalidade utilitarista e destruidora da natureza (BRÜSEKE, 2001). Schama (1996) critica os historiadores que vêem apenas uma relação de destruição e desencantamento da sociedade ocidental com a natureza, ao afirmar, com certa ironia, que:

[...] embora o tom dessas histórias seja compreensivelmente de penitência, elas divergem quanto à época em que o Ocidente caiu em desgraça. Para alguns historiadores, foi o Renascimento e as revoluções científicas dos séculos XVI e XVII que condenaram a terra a ser tratada pelo Ocidente como uma máquina que nunca quebraria. Lynn Wyite Jr., foi a invenção de um arado com arreios fixos, no século VII d. C., que selou o destino do planeta. A 'faca' do novo implemento 'atacava a terra'; a agricultura se transformou em guerra ecológica (SCHAMA, 1996, 23).

Os mais radicais afirmam que não foi só no Ocidente que houve tal dicotomia.

Segundo Schama (1996, 24), os paleolíticos habitantes das cavernas se teriam integrado à natureza ao invés de dominá-la, teriam rompido a cosmologia na qual a terra inteira era tida como sagrada. Segundo o autor, estaríamos condenados à destruição por nosso afastamento da natureza.

Utilizar tal perspectiva seria representar a visão hegemônica a partir de sua própria lógica de representação, e não perceber os mitos presentes em nossa relação com a natureza (SCHAMA, 1996, 24). A percepção das diferentes racionalidades presentes em nossa relação com a natureza abre a possibilidade de outras racionalidades para além da de um Homo economicus (LEFF, 2005). 
As duas principais correntes, nos extremos do pensamento ambiental na atualidade - o biocentrismo e o antropocentrismo -, continuam a manter a dicotomia entre cultura e natureza. É revelador o fato de autores, seja os que se aproximam do biocentrismo quanto os que se aproximam do antropocentrismo, terem continuado a postular a noção de mata virgem. Como já indicado, as conclusões práticas disso podem ser: postular a retirada de comunidades tradicionais de áreas em que haja ainda uma mata virgem por serem elas destruidoras; ou postular a permanência das comunidades tradicionais na mata virgem, por serem elas uma parte da natureza, que viveriam supostamente em harmonia com ela. De qualquer forma, continuam reinantes a dicotomia cultura e natureza e a incompreensão de nossas relações com o ambiente em que vivemos.

Na atualidade, o debate sobre a permanência ou não de “comunidades tradicionais” no interior de unidades de conservação é uma arena nodal desse conflito de representações. O debate pode ser sintetizado em duas posições: por um lado, os ambientalistas puros vão se pautar em pesquisas que indicam a redução da biodiversidade, em unidades de conservação que tentam manter "comunidades tradicionais” em seu interior, e acusam essas comunidades de tenderem a aderir ao modo de vida "moderno" e consumista e, com isso, desequilibrar a relação que têm com seu ecossistema. Por outro lado, os socioambientalistas vão indicar como, em muitos casos, foi graças à ação protetora das comunidades tradicionais que certas áreas foram preservadas de formas de exploração altamente destrutivas, enfatizando seu direito ancestral, indicando ainda que, mesmo que haja reduções pontuais da biodiversidade, as comunidades são capazes de manter um dado equilíbrio no ecossistema. Os socioambientalistas apostam na capacidade de inventividade dessas comunidades de melhorar a qualidade de vida, preservando um modo de vida diferenciado que não implique rompimento da capacidade de resiliência do ecossistema em que vivem.

Trata-se de um debate sofisticado. Cientistas foram chamados à arena pública para o debate (FERREIRA, 2003), mas não escapam aos pressupostos não-acadêmicos, a valores e a apostas em projetos de futuro. O fundamental aqui é perceber que as experiências das últimas três décadas de instalação de reservas extrativistas deveriam, justamente, romper a dicotomia natureza e cultura, ao mostrar formas de convivência viáveis em longo prazo, da floresta com comunidades ligadas à sociedade global, pelo menos essa é a aposta dos idealizadores das reservas extrativistas. A permanência do debate, porém, mostra que isso não aconteceu.

As ciências ambientais ainda oscilam entre dois pressupostos sobre a natureza humana: por um lado, o equívoco de postular uma natureza humana com um Homo devastans, para o qual reduzir a biodiversidade seria da natureza de toda ação humana. Se a nossa 
condição humana permitiu, na atualidade, que alguns pensassem o ser humano como um Homo economicus e a natureza como um depósito inesgotável de mercadorias é um equívoco generalizar tal condição parcial e situada no tempo e no espaço.

Por outro lado, deve-se ter cautela contra outra ideia, ainda presente nas ciências ambientais atuais sobre a natureza humana, a saber: a de que o ser humano pode ser um Selvagem Ecologicamente Nobre. Ou seja, projetar uma naturalização em algumas sociedades (tradicionais) como se estas vivessem em perfeita harmonia com a natureza; como se as sociedades "tradicionais" - ou seja, aquelas que têm modos de vida diferentes do consumista, socialmente injusto e ecologicamente insustentável, o modo de vida moderno - fosse composto por idealizados Selvagens Ecologicamente Nobres que fariam parte da natureza (BALÉE, 1998).

Balée (2003) pesquisa comunidades indígenas sul-americanas que produziram nichos ecológicos deferentes e ampliaram a diversidade de espécies no ambiente em que viveram. Desta forma, ele se insurge contra o erro desses dois extremos de uma "natureza humana". Demonstra que não há uma "natureza humana a priori”, que determina a relação da sociedade humana com a natureza, dependendo das interações culturais (econômicas, políticas, sociais) que configurações sociais estabelecem no ambiente que habitam sua interação pode ampliar ou reduzir a biodiversidade, seu desenvolvimento pode ser mais ou menos viável em longo prazo. De qualquer forma, quando partimos de uma natureza humana a priori, a tendência é reforçar a ideia de mata virgem: no primeiro caso, ignorando ou silenciando sobre os seres humanos que vivem em contato com a "mata” e suas inter-relações; no segundo caso, naturalizando as populações que têm contato com a "mata" e as consequências de sua ação. Em ambos os casos, o apelo a uma natureza humana vem acompanhado da dualidade natureza versus cultura.

Não é tão simples fugir de tal dicotomia. Ela faz parte de nossa visão de mundo. Já há muito se demonstrou que as teorias científicas têm com o senso comum um terreno em comum, um conjunto de pressupostos que formam nossa visão de mundo. Se a metodologia, a lógica e as teorizações formais são a parte visível do conhecimento científico, tal como em um iceberg, há uma parte encoberta, invisível, abaixo do nível da água, que são os pressupostos que os cientistas compartilham com o restante da sociedade. Desta forma, reconhece-se que a produção científica é parte da produção cultural geral de uma sociedade (KUHN, 1982; PRIGOGINE; STENGERS, 1997, 1). Por isso, por mais que se procure produzir modelos e teorias para superarem a dicotomia natureza versus cultura, a tendência é 
recorrentemente resvalar novamente para a dicotomia, assim como ocorre na dicotomia sujeito versus objeto.

Morin (1999) já argumentava que, para superar a atual crise ambiental, precisamos mudar nossa forma de pensar. Santos (1995) já argumentou que mudar nossa forma de pensar não demanda uma atitude voluntarista - uma espécie de mudança de atitude individual -, mas uma reforma em nossa forma de Ser, ou melhor, "precisamos aprender a ser aí (dasein), no planeta” (MORIN; KERN, 2005: 177), de forma que não tenhamos mais a pretensão de domínio da natureza, mas possamos “dialogar” com ela.

Se Morin (1999) estiver correto, a reforma pode começar pelo pensamento. Não há duvidas, porém, de que ela não pode se esgotar aí, mas deve mudar nosso paradigma da relação moderna com a natureza. É preciso não ser imediatistas ou um otimista ingênuo, pois não há garantias dos rumos ou ritmos de uma transformação paradigmática, uma vez que se trata de transformações de longo prazo. O conflito de representações que faz ressurgir a mata virgem, o "vazio demográfico" e o silenciamento sobre o "Outro”, que, às vezes, acompanha sua eliminação física, é apenas parte desse processo de transformação de longo prazo.

\section{$\mathrm{VI}$ - Considerações finais}

A abordagem aqui efetuada sobre mata virgem enquanto elemento componente de um mito é, sem dúvida, heterodoxa. Não se procurou construir uma teoria geral sobre o fenômeno, mas girar em torno dele, observando de diferentes perspectivas, procurando compreendê-lo em sua multidimensionalidade e explicá-lo de forma não-linear. Perspectiva que parece necessária para fazer frente à atual crise ambiental e perceber os tênues fios que conectam os fenômenos.

Todavia, o elemento central de interpretação foi o de pensar tal fenômeno em sua historicidade, não obscurecendo sua formação em um inconsciente coletivo primevo, mas entendendo-o como um fenômeno histórico, datado e complexo, intimamente ligado a uma sociedade que tentou se conceber acima e independente do mundo natural, ao qual poderia dominar e impor seus desejos. Talvez, em uma sociedade que aprenda a co-habitar no Planeta Terra (MORIN; KERN, 2005), o mito moderno da natureza intocada venha a encontrar uma data de fim, em nosso imaginário (seja em suas formulações científicas ou produzidas pelo senso comum), ou seja, talvez quando aprendermos que podemos "com-viver" com a floresta aprenderemos que não há mata virgem. 


\title{
DEEP INSIDE THE VIRGIN FOREST: the complexity of a mytical element in the Western imaginary about nature
}

\begin{abstract}
The virgin forest is a recurrent element in the Brazilian social imaginary. Although the mistake in considering "virgin" the forested areas has already been proved, human action, even indirect, left marks throughout the planet. This essay seeks to understand the reasons for the persistence of the term virgin forest in our imaginary. It is postulated that the expression "virgin forest" is part of a modern myth about nature; it is a "misunderstanding" that belongs to the ethnocentric culture; it is an ideology that justifies the Western domination; it is an appropriated representation and has been reelaborated in different social configurations; it is a long-lasting element that is anchored in the disjunction of nature and culture, which is part of the hegemonic world view in the West.
\end{abstract}

Keywords: Myth. Representation. Nature.

\section{Referências}

ALTIERI, M. Agroecologia: bases científicas para uma agricultura sustentável. Tradução Eli Lino de Jesus, Patrícia Vaz. Guaíba: Agropecuária, 2002.

BALÉE, W. Advances in Historical Ecology. New York: Columbia University Press, 1998.

. Diversidade amazônica e a escala humana do tempo. In: SIMPÓSIO DE

ETNOBIOLOGIA E ETNOECOLOGIA DA REGIÃO SUL, 1., 2003, Florianópolis. Anais. Florianópolis: UFSC, 2003. p. 14-28.

BAUMAN, Z. Modernidade e ambivalência. Tradução Marcus Penchel. Rio de Janeiro: J. Zahar, 1999.

BERKES, F. Sistemas sociais, sistemas ecológicos e direitos de apropriação de recursos naturais. In: VIEIRA, P. F.; BERKES, F.; SEIXAS, C. S., Gestão integrada e participativa de recursos naturais: conceitos, métodos e experiências. Florianópolis: Secco/APED, 2005. p. 47-72.

BERNARDES, L. M. C.. O problema das “frentes pioneiras” no Estado do Paraná. Revista Brasileira de Geografia. v. 15, n. 3, jul./set. 1953. p. 3-52,

BRÜSEKE, Fraz Josef. A técnica e os riscos da modernidade. Florianópolis: Editora da UFSC, 2001.

BURKE, P. Variedades de história cultural. Rio de Janeiro: Civilização Brasileira, 2000.

CARVALHO, E. B. A Modernização do Sertão: Terras, Florestas, Estado e Lavradores na Colonização de Campo Mourão, Paraná, 1939-1964. 2008. Tese (Doutorado em História) Programa de Pós-Graduação em História da Universidade Federal de Santa Catarina - USFC. Florianópolis. 
CARVALHO, E. B. de; NODARI, E. S. A Percepção na transformação da paisagem: os agricultores no desflorestamento de Engenheiro Beltrão - Paraná, 1948-1970. História, São Paulo, v. 26, n. 2, 2007. p. 269-287.

CORRÊA, D. S. Descrições de paisagens - construindo vazios humanos e territórios indígenas na capitania de São Paulo ao final do século XVIII. Varia História, Belo Horizonte, v. 24, n. 39, 2008. p. 135-152.

COSTA, K. S. Intervenções humanas na natureza amazônia (século XVII ao XIX). Ciencia \& Ambiente, Santa Maria, v. 1, n. 1. 1990. p. 81-96, jul.

DIEGUES, A. C. S. O mito moderno da natureza intocada. 2. ed. São Paulo: HUCITET, 1998.

ELIAS, N. Os Alemães: A luta pelo poder e a evolução do habitus no século XIX e XX. Rio de Janeiro: J. Zahar, 1997.

FERREIRA, L. da C. Dimensões Humanas da Biodiversidade: Conflitos em torno de Áreas Protegidas no Brasil. Disponível em: <http://www.chf.ufsc.br/ ppgsp>. Acesso em: 26 mar. 2003.

GINZBURG, C. História Noturna: Decifrando o sabá. São Paulo: Companhia das Letas, 1991.

GRÜN, M. Ética e Educação Ambiental: A conexão necessária. 3. ed. Campinas: Papirus, 1996.

HOLANDA, S. B. de. Visão do Paraíso: Os motivos edênicos no descobrimento e colonização do Brasil. 6. ed. São Paulo: Brasiliense, 1996.

KALAMPALIKIS, N. Mitos e representações sociais. In: PAREDES, E. C.; JODELET, D. (Orgs.). Pensamento mítico e representações sociais. Cuiabá: EdUFMT, 2009. p. 85-122.

KUHN, T. S. A estrutura das revoluções científicas. São Paulo: Perspectiva, 1982.

LEFF, E. Construindo a História Ambiental da América Latina. Tradução de Ely Bergo de Carvalho. Esboços, Florianópolis, n. 1, v. 13, 2005. p. 11-30,

MAACK, R. Geografia física do Estado do Paraná. 2. ed. Rio de Janeiro: J. Olympio, Curitiba: Secretaria da Cultura e do Esporte do governo do Estado do Paraná, 1981.

MONBEING, P. Pioneiros e Fazendeiros de São Paulo. Tradução de Ary França e Raul de Andrade e Silva. São Paulo: HUCITEC, 1984.

MORAN, E. F. Adaptabilidade Humana: uma introdução à antropologia ecológica. São Paulo: Edusp, 1994.

MORIN, E. Ciência com Consciência. 3. ed. Rio de Janeiro: Bertrand Brasil, 1999.

MORIN, E. O método III: O conhecimento do conhecimento/1. 2. ed. Portugal: Edições Europa-América, 1996. 
MORIN, E.; KERN, A. B. Terra-Pátria. Tradução de Paulo Neves. Porto Alegre: Sulina, 2005.

MOSCOVICI, S. Apresentação. In: PAREDES, E. C.; JODELET, D. (Orgs.). Pensamento mítico e representações sociais. Cuiabá: EdUFMT, 2009. p. 11-21.

MOTA, L. T. As Guerras dos Índios Kaingang: A História épica dos índios Kaingang no Paraná. Maringá: EDUEM, 1994.

NOVO Aurélio Século XXI. [S.l.]: Ed. Nova Fronteira, 200?. 1 CD-ROM. Versão 3.0.

PRIGOGINE, I.; STENGERS, I. A nova aliança: metamorfose da ciência. 3. ed. Brasília: Editora UnB, 1997.

RIBEIRO, R. F. Sertão, lugar deserto: o Cerrado na cultura de Minas Gerais. Belo Horizonte: Autêntica, 2006.

SAHLINS, M. História e Cultura: Apologias a Tucídides. Tradução de Maria Lucia de Oliveira. São Paulo: J. Zahar, 2006.

SAID, E. W. Cultura e Imperialismo. Tradução de Denise Bottman. São Paulo: Companhia das Letras, 1995.

SANTOS, B. de S. Um discurso sobre as ciências. 7. ed. Porto (Portugal): Afrontamento, 1995.

SCHAMA, S. Paisagem e Memória. São Paulo: Companhia das Letras, 1996.

SILVA, F. C. T. da. História das paisagens. In: CARDOSO, C. F.; VAINFAS, R. (Orgs.). Domínios da História: Ensaios de teoria e metodologia. Rio de Janeiro: Campus, 1997. p. 203-216.

THOMAS, K. O homem e o mundo natural: mudanças de atitude em relação às plantas e aos animais, 1500-1800. Tradução de João Roberto Martins Filho, São Paulo: Companhia das Letras, 1996.

TOMAZI, N. D. Construções e silêncios sobre a (re)ocupação da região norte do estado do Paraná. In: DIVAS, R. B.; GONÇALVES, J. H. R. (Orgs.). Maringá e o Norte do Paraná: estudos de história regional. Maringá: EDUEM, 1999. p. 51-86.

Recebido em: Julho/2010

Aprovado em: Setembro/2010 